\title{
Desmids (Zygnematophyceae) from the littoral zone of an urban artificial lake: taxonomic aspects and geographical distribution
}

Desmídias (Zygnematophyceae) da zona litorânea de um lago artificial urbano: aspectos taxonômicos e distribuição geográfica

\section{Camila Akemy Nabeshima Aquino ${ }^{1,2 *}$, Gabriela Medeiros ${ }^{1,2}$, Jascieli Carla Bortolini ${ }^{3}$, Cinthia Coutinho Rosa Favaretto ${ }^{1,2}$, Douglas Ticiani ${ }^{1}$, Fiorindo José Cerqueira ${ }^{1}$ and Norma Catarina Bueno ${ }^{1,2}$}

\begin{abstract}
${ }^{1}$ Programa de Pós-graduação em Conservação e Manejo de Recursos Naturais, Universidade Estadual do Oeste do Paraná - UNIOESTE, Rua Universitária, 2019, Jardim Universitário, CEP 85819-110, Cascavel, PR, Brasil

${ }^{2}$ Laboratório de Ficologia, Universidade Estadual do Oeste do Paraná - UNIOESTE, Rua Universitária, 2019, Jardim Universitário, CEP 85819-110, Cascavel, PR, Brasil

${ }^{3}$ Departamento de Botânica, Universidade Federal de Goiás - ICB, Avenida Esperança, s/n, CEP 74690-900, Goiânia, GO, Brasil

*e-mail: camilaakemy@yahoo.com.br
\end{abstract}

Cite as: Aquino, C.A.N. et al. Desmids (Zygnematophyceae) from the littoral zone of an urban artificial lake: taxonomic aspects and geographical distribution. Acta Limnologica Brasiliensia, 2018, vol. 30, e202.

Abstract: Aim: The aim of this study was to assess the taxonomic aspects and geographical distribution of the periphytic desmids from two different substrates in the littoral zone of an urban artificial lake. Methods: Samples of epiphytic and epilithic desmids were collected by grass and rock scraping, respectively, in two stations in the Cascavel municipal lake, Paraná, during April 2015, and March 2016 and 2017. In the laboratory, the taxa obtained from the samples were photographed and their morphometric characteristics recorded. The species composition of the desmid was characterized, and the frequency of occurrence as well as the geographic distribution of each taxon in the Paraná State were recorded. Results: We identified 35 taxa, distributed in 10 genera. The most representative were Closterium Nitzsch ex Ralfs and Cosmarium Corda ex Ralfs. A high occurrence of sporadic taxa $(60 \%)$ was observed and among the recorded taxa, the most frequent were Cosmarium pseudoconnatum Nordstedt var. pseudoconnatum and Desmidium grevillei (Kützing ex Ralfs) De Bary. Nine taxa were exclusive to the epilithic substrate and only Netrium digitus (Ralfs) Itzigsohn \& Rothe var. digitus was exclusive to the epiphytic substrate, while the remaining 25 taxa occurred in both substrates. Seven taxa are new records for the Paraná State. Conclusion: Although our results are of qualitative nature, they provide baseline data on the biogeographic distribution of taxa, which are crucial for future taxonomic and ecological studies that might contribute to the preservation of the biodiversity.

Keywords: aquatic biodiversity; Desmidiales; geographic distribution; lentic environment; periphytic algae.

Resumo: Objetivo: $\mathrm{O}$ objetivo deste estudo foi avaliar os aspectos taxonômicos e a distribuição geográfica das desmídias perifíticas de dois substratos diferentes na zona litorânea de um lago artificial urbano. Métodos: Amostras de desmídias epífitas e epilíticas foram coletadas por raspagem de 
gramíneas e rochas, respectivamente, em duas estações no lago municipal de Cascavel, Paraná, durante abril de 2015 e março de 2016 e 2017 . No laboratório, os táxons obtidos a partir das amostras foram fotografados e suas características morfométricas foram registradas. A composiçáo das espécies de desmídias foi caracterizada e a frequência de ocorrência, bem como a distribuição geográfica de cada táxon no Estado do Paraná foram registradas. Resultados: Nós identificados 35 táxons, distribuídos em 10 gêneros. Os gêneros mais representativos foram Closterium Nitzsch ex Ralfs e Cosmarium Corda ex Ralfs. Uma alta ocorrência de táxons esporádicos (60\%) foi observada, e entre os táxons registrados, os mais frequentes foram Cosmarium pseudoconnatum Nordstedt var. pseudoconnatum e Desmidium grevillei (Kützing ex Ralfs) De Bary. Nove táxons foram exclusivos para o substrato epilítico e somente Netrium digitus (Ralfs) Itzigsohn \& Rothe var. digitus foi exclusivo para o substrato epifítico, enquanto os demais 25 táxons ocorreram em ambos os substratos. Sete táxons são novas ocorrências para o estado do Paraná. Conclusão: Embora nossos resultados sejam de natureza qualitativa, eles fornecem uma base de dados sobre a distribuiçẫo biogeográfica dos táxons, os quais são cruciais para futuros estudos taxonômicos e ecológicos que podem contribuir para a preservação da biodiversidade.

Palavras-chave: algas perifíticas; ambiente lêntico; biodiversidade aquática; Desmidiales; distribuição geográfica.

\section{Introduction}

Landscapes are composed of different aquatic ecosystems. In these ecosystems, conditions of light and nutrients are appropriate for the development and establishment of microorganisms that are key elements for their functioning. Artificial lakes are remarkable components of the local and regional landscapes, in where a wide, but a still little-known diversity of microalgae can be found (Menezes et al., 2011a).

The periphyton is a complex assemblage of different microorganisms, including microalgae, cyanobacteria, microinvertebrates, and detritus attached to organic or inorganic substrates (Wetzel, 1983). Depending on the type of substrate to which they are attached, they are known as epilithon, if attached to rocky substrates, and epiphyton, if attached to aquatic plants (Wetzel, 1981; Fransceschini et al., 2010). Periphytic microalgae play key roles in the energy and matter cycles in the littoral zones (Vercellino \& Bicudo, 2006), being their temporal and spatial dynamics influenced by environmental conditions (Moschini-Carlos, 1999; Goldsborough \& Robinson, 1996).

The desmids belong to the class Zygnematophyceae (Phylum Charophyta) and are considered the greatest and most diverse group of the Infrakingdom Streptophyta (Gontcharov \& Melkonian, 2005; Ruggiero et al., 2015). They are important components of the structure of the periphyton community, due to the high diversity of taxa and of functional strategies (Felisberto et al., 2014).

Desmids are cosmopolitan and $k$ strategists that exhibit a wide variety of forms, being either unicellular or pseudofilamentous (Coesel, 1996). They are considered the geographically most studied group of algae due to their often appealing appearance (Coesel \& Krienitz, 2008). Desmids have a few truly planktonic representatives, which are mostly associated with periphyton, in mesotrophic to oligotrophic environments of slightly acid $\mathrm{pH}$, high temperatures and low electrical conductivity (Coesel, 1982, 1996; Černá \& Neustupa, 2010; Stamenkovič \& Hanelt, 2017). In addition, desmids are ecologically sensitive organisms to environmental changes and thus can be useful tools as bioindicators for the monitoring and management of aquatic environments (Coesel, 2001). For these reasons, taxonomic and floristic inventories, often ignored, become relevant for understanding the complex association of these organisms with the environment, and can contribute to the better knowledge of the biodiversity and the consequences of its changes (Meester \& Declerck, 2005).

The aim of this study was to assess the epilithic and epiphytic composition of desmids in the littoral zone of an urban artificial lake, as well as the geographic distribution of the taxa recorded, contributing to the knowledge on the desmid diversity of the Paraná State.

\section{Material and Methods}

\subsection{Study area}

The Cascavel River belongs to the Cascavel River basin and is the main water source of the municipality of Cascavel, Paraná. Its principal springs are located in the municipal lake region $\left(24^{\circ} 32^{\prime}\right.$ and $25^{\circ} 17^{\prime} \mathrm{S}$ and $53^{\circ} 05^{\prime}$ and $53^{\circ} 50^{\prime} \mathrm{W}$ ), which is placed in the Paulo Gorski Ecological Park (Casagrande, 1996). The Cascavel municipal lake (Figure 1) is supplied by several streams and has a drainage area of $117.5 \mathrm{~km}^{2}$. This lake is an 


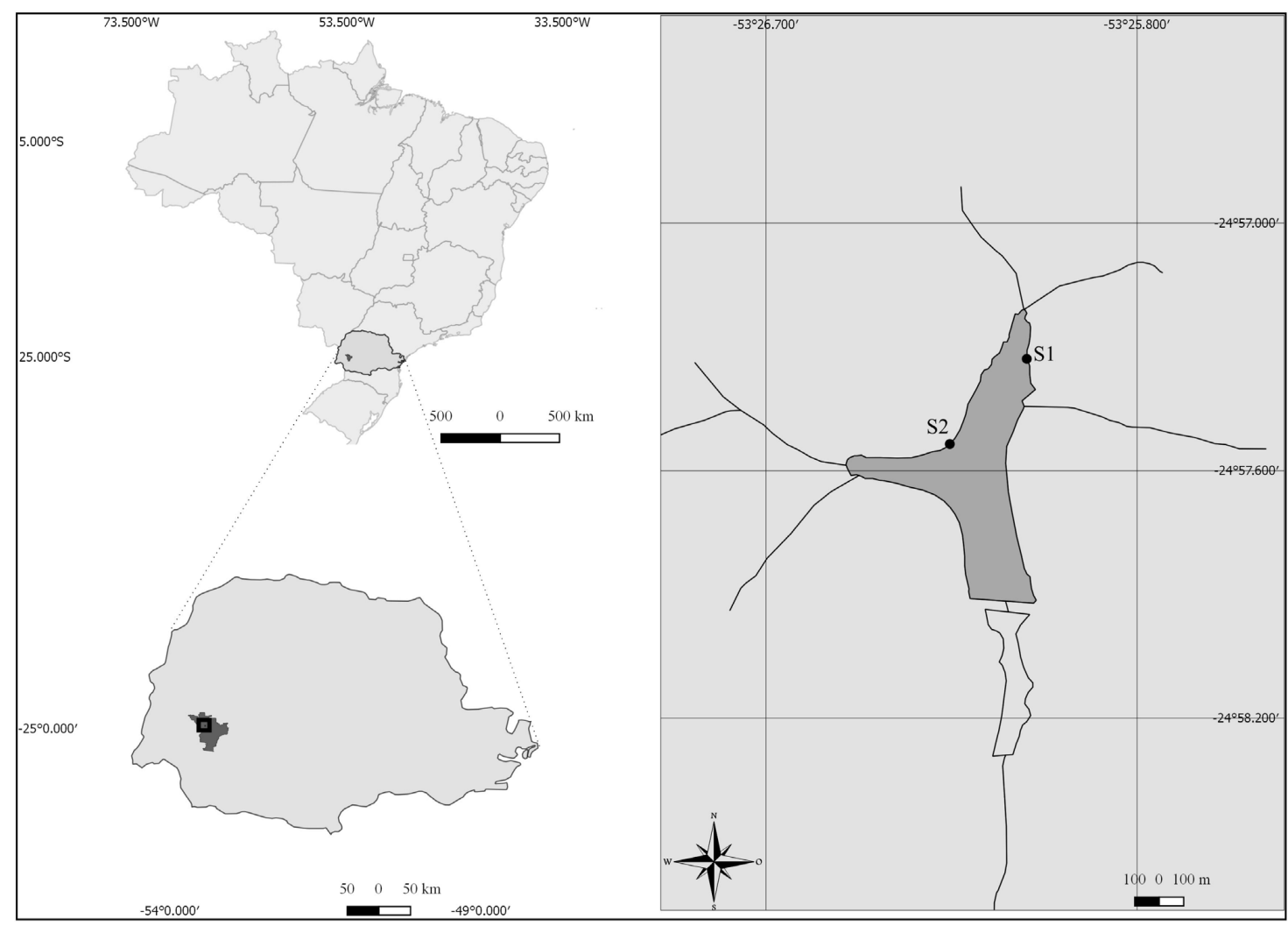

Figure 1. Location of the sampling stations in the Cascavel municipal lake, Paraná, Brazil (S1 - Station 1; S2 - Station 2).

artificial reservoir intended to the public supply and constitutes an important area of touristic visitation. During the last 20 years, the lake has been suffering from sedimentation of its margins, besides sewage discharges in its surroundings. This region has a humid-mesothermal subtropical climate, with a well-defined summer and winter periods and well-distributed rainfalls through the year (Alvares et al., 2014). Two sampling

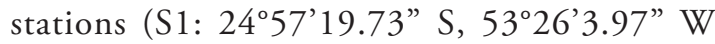
and S2: $\left.4^{\circ} 57^{\prime} 32.11^{\prime \prime} \mathrm{S}, 52^{\circ} 26^{\prime} 15.22^{\prime \prime} \mathrm{W}\right)$ were established in the lake. At each station, some environmental variables were measured with a Horiba U-50 multiparameter probe (Figure 1; Table 1).

\subsection{Sampling and laboratory analysis}

Collection of samples and measurement of environmental variables at each sampling station were performed during April 2015, and March 2016 and 2017 ( $\mathrm{n}=12$ ). Biological samples were collected from epiphytic and epilithic substrates in the littoral zone of the lake, by grass and rock scraping, respectively. Samples were properly stored and preserved in 1:1 Transeau solution (Bicudo \&
Table 1. Characterization of the sampling stations in the Cascavel municipal lake, Paraná, Brazil. Values of the abiotic variables are expressed as means and coefficients of variation (\%).

\begin{tabular}{ccccccc}
\hline & WT & pH & DO & EC & TDS & TUR \\
\hline S1 & 19.3 & 6.6 & 9.4 & 0.05 & 0.03 & 0.93 \\
& $(17 \%)$ & $(4 \%)$ & $(5 \%)$ & $(10 \%)$ & $(12 \%)$ & $(62 \%)$ \\
S2 & 21.3 & 6.4 & 10.1 & 0.05 & 0.03 & 28.40 \\
& $(22 \%)$ & $(5 \%)$ & $(16 \%)$ & $(49 \%)$ & $(48 \%)$ & $(12 \%)$ \\
\hline
\end{tabular}

References: WT - water temperature, ${ }^{\circ} \mathrm{C} ; \mathrm{pH}$; DO - dissolved oxygen, mg L ${ }^{-1}$; EC - electrical conductivity, $\mu \mathrm{S} \mathrm{cm}^{-1}$; TDS - total dissolved solids, $\mathrm{g} \mathrm{L}^{-1}$; TUR - turbidity, NTU; S1 - station 1; S2 - station 2.

Menezes, 2006). For qualitative analyses, an average of 10 temporary slides per sample was prepared, and the microalgae photographed and characterized morphometrically under 400 or $1000 x$ magnification with an Olympus trinocular microscope model CX31 with camera attached.

The systematic framework of the genera followed Bicudo \& Menezes (2006). Identification of Cosmarium and Actinotaenium was according to Prescott et al. (1981), and specialized scientific papers 
were used for other genera. Taxa were characterized morphometrically and their geographic distribution in the Paraná State recorded. Measurements were expressed in $\mu \mathrm{m}$ and represented by the symbols L: (length), W: (width), and I: (isthmus). The samples were deposited in the Herbarium of the State University of West Paraná (UNOP-Algae), Cascavel campus (Table 2).

The frequency of occurrence of the taxa in the samples (constancy $=\mathrm{C}$ ) was calculated according to Dajoz (2005). Taxa were classified as constant (C $\geq 70 \%)$, common $(30 \% \geq \mathrm{C} \leq 70 \%)$, sporadic $(10 \% \geq \mathrm{C} \leq 30 \%)$ or rare $(\mathrm{C} \leq 10 \%)$. Artificial keys to identify the taxa in each genus were constructed for those genera more than two taxa.

\section{Results and Discussion}

We recorded 35 taxa of desmids, distributed in 10 genera: Actinotaenium (Nägeli) Teiling (1), Closterium Nitzsch ex Ralfs (10), Cosmarium Corda ex Ralfs (12), Desmidium C. Agardh ex Ralfs (1), Euastrum Ehrenberg ex Ralfs (2), Micrasterias C. Agardh ex Ralfs (3), Netrium (Nägeli) Itzigsohn \& Rothe (2), Penium Brébisson ex Ralfs (2), Pleurotaenium Nägeli (1) and Staurastrum Meyen ex Ralfs (1). All recorded taxa are described below.

Actinotaenium cucurbitinum var. cucurbitinum (Bisset) Teiling f. minus (West \& G. S. West) Teiling, Bot. Not., 4: 376-426. 1954.

Basionym: Penium cucurbitinum f. minus West \& G. S. West, 1894.

Cells 2.2-2.8 times longer than wide. Semicells cylindrical, slightly attenuated toward the apex. Apex rounded. Median constriction with shallow sinus. Cell wall finely punctuated. Chloroplast with lamellae. One pyrenoid per semicell. L: 40.4-63.1 $\mu \mathrm{m}$; W: 14.4-27.6 $\mu \mathrm{m}$; I: 13.7-26.7 $\mu \mathrm{m}$. Figure 2

Geographic distribution in the Paraná State: First record of the taxon.

Frequency of occurrence: Common

Identification key for the taxa recorded in the genus Closterium

1. Cells slightly curved, almost straight or straight

2. Cell wall with fine longitudinal striae. .3

3. Apex rounded or truncated-rounded.......4

4. Pyrenoids 12-14

Closterium acerosum var. acerosum

4. Pyrenoids 4-6. Closterium kuetzingii var. kuetzingii

3. Apex truncated. .5

5. Cell length $216-233 \mu \mathrm{m}$

Closterium baillyanum var. baillyanum

5. Cell length $867.6 \mu \mathrm{m}$

.Closterium braunii

2. Cell wall smooth ...6

6. Cell length 344.9-388 $\mu \mathrm{m}$ .........................Closterium pseudolunula var. pseudolunula

6. Cell length 33.6-213.4 $\mu \mathrm{m}$................7

7. Chloroplast axial with 4-5 longitudinal lamellae and pyrenoids 1-3 ..Closterium navicula var.

navicula

7. Chloroplast axial divided transversally and pyrenoids 3-5.

Closterium closterioides var. closterioides

1. Cells lunate, curved or strongly curved ......8 8. Apex truncated

..Closterium tumidum var. tumidum

8. Apex rounded or rounded-conical .9

Table 2. Reference information of the examined samples collected in the Cascavel municipal lake and deposited in the Herbarium of the State University of West Paraná (UNOP-Algae), Cascavel, Paraná, Brazil.

\begin{tabular}{ccccc}
\hline UNOP-Algae & Collection date & Station & Geographical Coordinates & Collector \\
\hline 4490 & $01 / 03 / 2017$ & S1 & $24^{\circ} 57^{\prime} 19.73^{\prime \prime} \mathrm{S} 53^{\circ} 26^{\prime} 3.97^{\prime \prime}$ W & N.C. Bueno \\
4491 & $01 / 03 / 2017$ & $\mathrm{~S} 1$ & $24^{\circ} 57^{\prime} 19.73^{\prime \prime} \mathrm{S} 53^{\circ} 26^{\prime} 3.97^{\prime \prime} \mathrm{W}$ & N.C. Bueno \\
4492 & $01 / 03 / 2017$ & $\mathrm{~S} 2$ & $24^{\circ} 57^{\prime} 32.11^{\prime \prime} \mathrm{S} 52^{\circ} 26^{\prime} 15.22^{\prime \prime} \mathrm{W}$ & N.C. Bueno \\
4493 & $01 / 03 / 2017$ & $\mathrm{~S} 2$ & $24^{\circ} 57^{\prime} 32.11^{\prime \prime} \mathrm{S} 52^{\circ} 26^{\prime} 15.22^{\prime \prime} \mathrm{W}$ & N.C. Bueno \\
2617 & $05 / 03 / 2016$ & $\mathrm{~S} 1$ & $24^{\circ} 57^{\prime} 19.73^{\prime \prime} \mathrm{S} 53^{\circ} 26^{\prime} 3.97^{\prime \prime} \mathrm{W}$ & N.C. Bueno \\
2618 & $05 / 03 / 2016$ & $\mathrm{~S} 1$ & $24^{\circ} 57^{\prime} 19.73^{\prime \prime} \mathrm{S} 53^{\circ} 26^{\prime} 3.97^{\prime \prime} \mathrm{W}$ & N.C. Bueno \\
2615 & $05 / 03 / 2016$ & $\mathrm{~S} 2$ & $24^{\circ} 57^{\prime} 32.11^{\prime \prime} \mathrm{S} 52^{\circ} 26^{\prime} 15.22^{\prime \prime} \mathrm{W}$ & N.C. Bueno \\
2616 & $05 / 03 / 2016$ & $\mathrm{~S} 2$ & $24^{\circ} 57^{\prime} 32.11^{\prime \prime} \mathrm{S} 52^{\circ} 26^{\prime} 15.22^{\prime \prime} \mathrm{W}$ & N.C. Bueno \\
4187 & $04 / 04 / 2015$ & $\mathrm{~S} 1$ & $24^{\circ} 57^{\prime} 19.73^{\prime \prime} \mathrm{S} 53^{\circ} 26^{\prime} 3.97^{\prime \prime} \mathrm{W}$ & N.C. Bueno \\
4188 & $04 / 04 / 2015$ & $\mathrm{~S} 1$ & $24^{\circ} 57^{\prime} 19.73^{\prime \prime} \mathrm{S} 53^{\circ} 26^{\prime} 3.97^{\prime \prime} \mathrm{W}$ & N.C. Bueno \\
4185 & $04 / 04 / 2015$ & $\mathrm{~S} 2$ & $24^{\circ} 57^{\prime} 32.11^{\prime \prime} \mathrm{S} 52^{\circ} 26^{\prime} 15.22^{\prime \prime} \mathrm{W}$ & N.C. Bueno \\
4186 & $04 / 04 / 2015$ & $\mathrm{~S} 2$ & $24^{\circ} 57^{\prime} 32.11^{\prime \prime} \mathrm{S} 52^{\circ} 26^{\prime} 15.22^{\prime \prime} \mathrm{W}$ & N.C. Bueno \\
\hline
\end{tabular}


9. Cell wall with striae.

Closterium malmei var. malmei

9. Cell wall smooth Closterium incurvum var. incurvum.

Closterium acerosum Ehrenberg ex Ralfs var. acerosum, British Desmidieae 164, pl. 27, figs a,b,d-e. 1848 .

Cells 11-17 times longer than wide. Cells slightly lunate, with ventral margin slightly concave and dorsal margins slightly convex, tapering towards both ends. Apex truncated-rounded, often angular. Cell wall colorless or brownish striated. Chloroplast axial. Pyrenoids 12-14. L: 493.8-598.4 $\mu \mathrm{m}$; W: 29-50.3 $\mu \mathrm{m}$. Figures 3-5

Geographic distribution in the Paraná State: First record of the taxon.

Frequency of occurrence: Sporadic

Closterium baillyanum (Brébisson ex Ralfs) Brébisson var. baillyanum, Mém. Soc. Imp. Sc. Nat. Cherbourg, 4: 151, pl. 1-2. 1856.

Basionym: Closterium didymotocum Ralfs var. baillyanum Brébisson in Ralfs Brit. Desm., 169. 1848.

Cells 6-10 times longer than wide. Cells slightly curved with dorsal margin slightly convex; ventral margin a bit concave, sometimes more straight in the median portion. Apex truncated. Cell wall with fine striae and dense punctuations, mainly in the apical region. Chloroplast axial. Pyrenoids 5-8, arranged in a median series. L: $216-233.6 \mu \mathrm{m}$; W: 23.8-35.9 $\mu \mathrm{m}$. Figure 6

Geographic distribution in the Paraná State: Bortolini et al. (2009); Menezes et al. (2011a); Aquino et al. (2014).

Frequency of occurrence: Sporadic

Closterium braunii Reinsch, Abh. Senck. Naturf. Ges., 6 (2): 138, pl. 20C, fig. 1: 1-5. 1867.

Cells 12 times longer than wide. Cells slightly curved with dorsal margin convex and ventral margin a bit concave. Apex truncated. Cell wall finely striated. Chloroplast axial. Pyrenoids 12-14. L: $867.6 \mu \mathrm{m}$; W: $69.3 \mu \mathrm{m}$. Figure 7-9.

Geographic distribution in the Paraná State: First record of the taxon.

Frequency of occurrence: Rare

Closterium closterioides (Ralfs) A. Louis \& Peeters var. closterioides, Bull. Jard. Bot. Natl. Belg., 37: 410, pl. 13, fig. 119. 1967.

Basionym: Penium closterioides Ralfs 152, pl. 34: fig. 4.1848 .

Cells 3-4 times longer than wide. Cells straight, elliptic to fusiform, with both dorsal and ventral margins equally convex. Apex truncated-rounded.
Cell wall smooth, colorless. Chloroplast axial divided incompletely and transversally. Pyrenoids 3-5, arranged in a median series. L: 91.9-142.6 $\mu \mathrm{m}$; W: 23.8-57.5 $\mu \mathrm{m}$. Figure 10.

Geographic distribution in the Paraná State: Algarte et al. (2006); Felisberto \& Rodrigues (2007, 2012); Bortolini et al. (2009, 2010a); Aquino et al. (2014); Burack et al. (2016).

Frequency of occurrence: Sporadic

Closterium incurvum Brébisson var. incurvum, Mém. Soc. Imp. Sci. Nat. Cherbourg, 4: 150, pl. 2, fig. 47. 1856.

Cells 2-4 times longer than wide. Cells lunate, strongly curved, dorsal margin convex and ventral margin concave, with pointed-rounded poles. Cell wall smooth or hyaline to brownish. Chloroplast axial. Pyrenoids 4-7, arranged in a median series. L: 33.6-72.5 $\mu \mathrm{m}$; W: $15-18.3 \mu \mathrm{m}$. Figure 11 .

Geographic distribution in the Paraná State: Picelli-Vicentim (1984); Bittencourt-Oliveira \& Castro (1993); Felisberto \& Rodrigues (2007); Biolo et al. (2008); Bortolini et al. (2009).

Frequency of occurrence: Common

Closterium kuetzingii Brébisson var. kuetzingii, Mém. Soc. Imp. Sc. Nat. Cherbourg, 4: 156, pl. 2, fig. 40. 1856.

Cells 15-22 times longer than wide. Cells almost straight; median portion fusiform with dorsal and ventral margins equally convex. Apex rounded and slightly curved. Cell wall finely striated. Chloroplast axial. Pyrenoids 4-6, arranged in a median series. L: 224.5-391.8 $\mu \mathrm{m}$; W: 14.2-17.2 $\mu \mathrm{m}$. Figure 12.

Geographic distribution in the Paraná State: Andrade \& Rachou (1954); Bittencourt-Oliveira \& Castro (1993); Cecy et al. (1997); Algarte et al. (2006); Menezes et al. (2011a); Aquino et al. (2014).

Frequency of occurrence: Common

Closterium malmei Borge var. malmei, Ark. Bot., 1: 79, pl. 1, fig. 21. 1903.

Cells 2-4 times longer than wide. Cells strongly curved, not inflated in the median region. Apex rounded conical with a thickening in the interior wall. Cell wall colorless to brownish with longitudinal striae. Chloroplast axial. Pyrenoids 9, arranged in a median series. L: 91.3-213.4 $\mu \mathrm{m}$; W: 32.9-47.9 $\mu \mathrm{m}$. Figure 13-15.

Geographic distribution in the Paraná State: Algarte et al. (2006); Aquino et al. (2014).

Frequency of occurrence: Sporadic

Closterium navicula (Brébisson) J. Lütkemüller var. navicula, Beitr. Biol. Pfl. Breslau, 8(3): 395, 405, 408. 1902. 
Basionym: Penium navicula Brébisson 146, pl 2, fig. 37. 1856.

Cells 3-4 times longer than wide. Cells straight, elliptic to fusiform, with both dorsal and ventral margins equally convex and truncated-rounded apex. Cell wall smooth, colorless. Chloroplast axial with 4-5 longitudinal lamellae. Pyrenoids 1-3, arranged in a median series. L: 34.4-52.6 $\mu \mathrm{m}$; W: 11.6-15.3 $\mu \mathrm{m}$. Figure 16.

Geographic distribution in the Paraná State: Algarte et al. (2006); Felisberto \& Rodrigues (2007); Bortolini et al. (2009); Menezes et al. (2011a); Aquino et al. (2014); Felisberto et al. (2014); Burack et al. (2016).

Frequency of occurrence: Common

Closterium pseudolunula Borge var. pseudolunula, Ark. Bot., 8 (13): 3, pl. 1, fig. 2. 1909.

Cells 6-8 times longer than wide. Cells straight, elliptic to fusiform with dorsal margin slightly convex and ventral margin straight. Apex truncated-rounded. Cell wall smooth. Chloroplast axial. Pyrenoids not observed. L: 344.9-388 $\mu \mathrm{m}$; W: 40-57.4 $\mu \mathrm{m}$. Figure 17-19.

Geographic distribution in the Paraná State: Bittencourt-Oliveira (1993).

Frequency of occurrence: Sporadic

Closterium tumidum L. N. Johnson var. tumidum, Bull. Torrey Bot. Club, 22: 291, pl. 232, fig. 4, 31. 1895.

Basionym: Closterium cornu Ehrenberg ex Ralfs 176, pl. 30: figs. 6f- g. 1848.

Cells 5 times longer than wide. Cells curved with dorsal margins convex and ventral margin slightly straight; truncated apex. Cell wall smooth, yellowish or brownish. Chloroplast axial. Pyrenoids 3-5, arranged in a median series. L: 72.6-80.3 $\mu \mathrm{m}$; W: $13.5-14.8 \mu \mathrm{m}$. Figure 20.

Geographic distribution in the Paraná State: Ferreira et al. (2011); Aquino et al. (2014).

Frequency of occurrence: Sporadic

Identification key for the taxa recorded in the genus Cosmarium

1. Cell wall smooth or finely punctuated .......2

2. Cell wall smooth

Cosmarium obsoletum var. obsoletum

2. Cell wall finely punctuated ....3

3. Apex rounded or rounded-truncated ....4 4. Shallow median constriction Cosmarium pseudoconnatum var. pseudoconnatum

4. Deep median constriction
5. Pyramida.l semicells ..Cosmarium pseudopyramidatum var. excavatum

5. Subtrapeziform semicells

Cosmarium candianum var. candianum

3. Apex truncated .6

6. Circular semicell

..Cosmarium dispersum var. dispersum

6. Trilobular semicell

Cosmarium trilobulatum var. trilobulatum

1. Cell wall with granules, spines or warts .....7

7. Apex retuse to straight

.Cosmarium quadrum var. minus

7. Apex rounded and truncated-rounded ....8

8. Cell wall with spines

.Cosmarium denticulatum var. ovale

8. Cell wall with granules .9

9. Cell length 43.8-49 $\mu \mathrm{m}$ .Cosmarium subspeciosum var. subspeciosum

9. Cell length 73.7-92 $\mu \mathrm{m}$ 10

10. Cell face ornamented with triangular granules ..............Cosmarium decoratum

10. Cell face ornamented without granules .11

11. Cells oblong-elliptic

Cosmarium margaritatum var. margaritatum $\mathrm{f}$. margaritatum

11. Cells pyramidal-truncated .Cosmarium subspeciosum

var. validius

Cosmarium candianum Delponte var. candianum, Mém. R. Accad. Sci. Torino, 28: 113, pl. 8, fig. 1-6. 1877.

Cells once longer than wide. Semicells semicircular with rounded lateral and apical margins. Apex rounded. Cell wall finely and closely punctate. Median constriction deep. Linear median sinus closed. Chloroplast axial. Pyrenoids 2 per semicell. L: $45-50 \mu \mathrm{m}$; W: $43.3-48 \mu \mathrm{m}$; I: $14.5-17 \mu \mathrm{m}$. Figure 21 .

Geographic distribution in the Paraná State: Picelli-Vicentim (1984); Bortolini et al. (2010b); Menezes et al. (2013); Aquino et al. (2014, 2016).

Frequency of occurrence: Sporadic

Cosmarium decoratum West \& G.S. West, Trans. Linn. Soc. London, Bot., II, 5(2): 61, pl. 7 , fig. 21. 1895.

Cells 1.3 times longer than wide. Semicells semicircular to pyramidal truncated. Apex rounded-truncated. Cell wall granular, with hexagonal series arranged in dense granules, with 


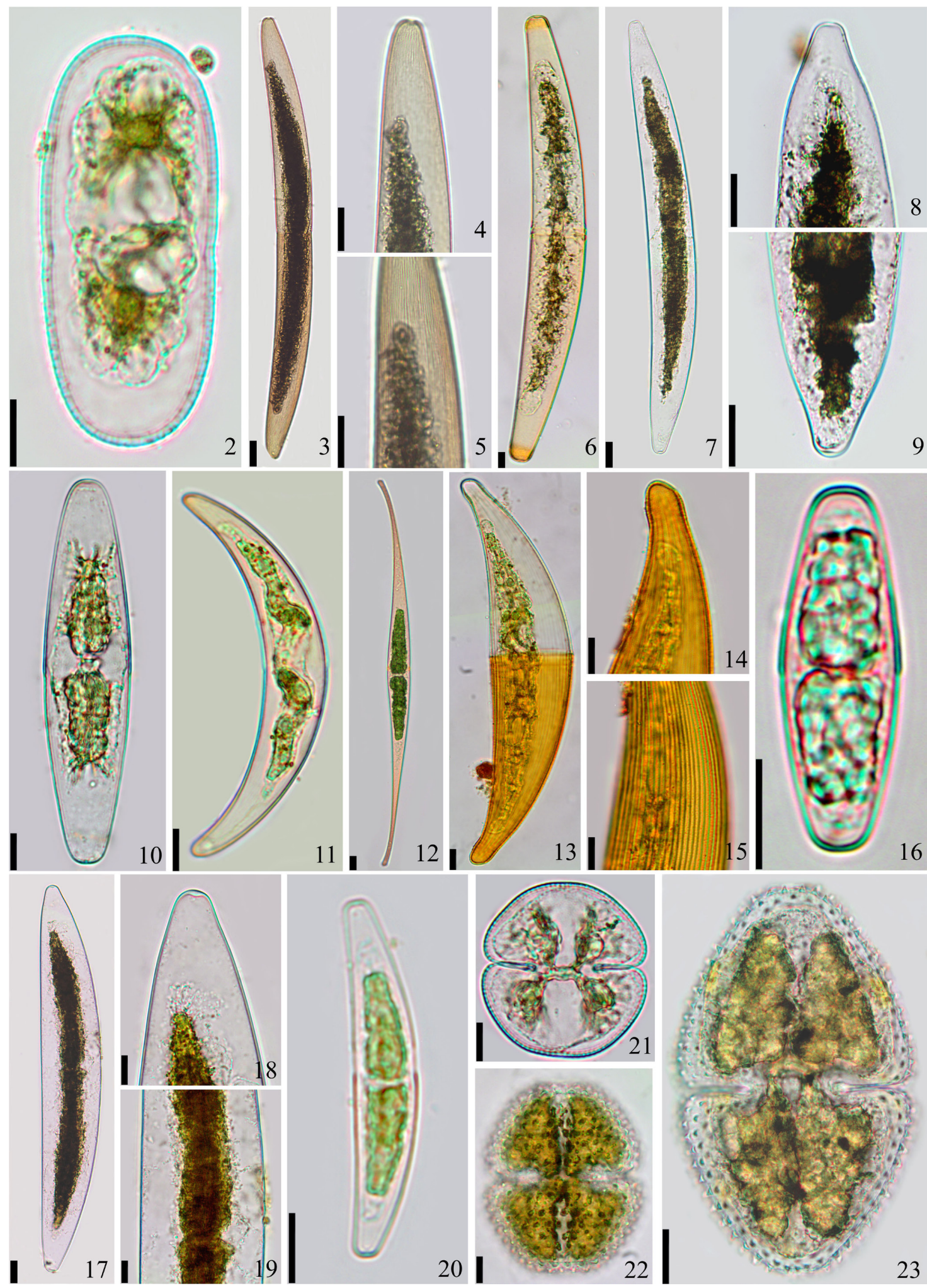

Figures 2-23. Desmids of the Cascavel municipal lake, Paraná, Brazil. 2. Actinotaenium cucurbitinum var. cucurbitinum f. minus 3-5. Closterium acerosum var. acerosum 4-5. Detail of the cell wall 6. C. baillyanum var. baillyanum 7-9. C. braunii 8-9. Detail of the apex 10. C. closterioides var. closterioides 11. C. incurvum var. incurvum 12. C. kuetzingii var. kuetzingii 13-15. C. malmei var. malmei 14. Detail of the Apex 15. Detail of the cell wall 16. C. navicula var. navicula 17-19. C. pseudolunula var. pseudolunula 18. Detail of the Apex 19. Detail of the cell wall 20. C. tumidum var. tumidum 21. Cosmarium candianum var. candianum 22. C. decoratum 23. C. denticulatum var. ovale. Scale $10 \mu \mathrm{m}$. 
triangular pores in the central region. Median constriction deep. Sinus slightly open in the proximal region. Chloroplast axial. Pyrenoids 2 per semicell. L: 73.7-85.5 $\mu \mathrm{m}$; W: 55-64.6 $\mu \mathrm{m}$; I: 24.4-28.4 $\mu \mathrm{m}$. Figure 22.

Geographic distribution in the Paraná State: Felisberto \& Rodrigues (2010a); Biolo et al. (2013); Aquino et al. (2014, 2016).

Frequency of occurrence: Sporadic

Cosmarium denticulatum Borge var. ovale Grönblad, Acta Soc. Sci. fenn.: sér. B, 2(6): 17, pl. 5, fig. 103. 1945.

Cells 1.6 times longer than wide. Semicells pyramidal with lateral and apical margins denticulate; lateral margins convex, sometimes slightly straight, with rounded-truncated apex. Cell wall with spines. Median constriction deep. Linear median sinus closed. Chloroplast axial. Pyrenoids not observed. L: $139 \mu \mathrm{m}$; W: $83.7 \mu \mathrm{m}$; I: $31 \mu \mathrm{m}$. Figure 23.

Geographic distribution in the Paraná State: Felisberto \& Rodrigues (2010a); Bortolini et al. (2010b); Aquino et al. (2014).

Frequency of occurrence: Rare

Cosmarium dispersum L. N. Johnson f. dispersum L. N. Johnson, Bull. Torrey Bot. Club, 22: 297, pl. 233, fig. 19. 1895.

Cells about as long as wide. Semicells approximately circular, with truncated apex. Cell wall finely punctuated, showing approximately 18 undulations in the semicell margins. Median constriction deep. Linear sinus closed. Chloroplast axial. Pyrenoids 2 per semicell. L: 45.2-47.5 $\mu \mathrm{m}$; W: 39.5-42.2 $\mu \mathrm{m}$; I: 14.6-14.8 $\mu \mathrm{m}$. Figure 24 .

Geographic distribution in the Paraná State: Aquino et al. $(2014,2016)$.

Frequency of occurrence: Sporadic

Cosmarium margaritatum (P. Lundell) Roy \& Bisset var. margaritatum f. margaritatum, Jd. Bot., 27(1): 194. 1886.

Basionym: Cosmarium latum Brébisson var. margaritatum P. Lundell, Nova Acta R. Soc. Scient. Upsal.: sér. 3, 8(2): 26. 1871.

Cells 1.2 times longer than wide. Semicells subretangular, sometimes ellipsoidal-subretangular, with rounded angles. Apex straight or very slightly convex. Cell wall uniformly granulate, with 28 to 32 solid granules distributed on the margins of the semicell. Median constriction deep, linear median sinus. Chloroplast axial. Pyrenoids 2 per semicell. L: $78.6 \mu \mathrm{m}$; W: $64 \mu \mathrm{m}$; I: $21.3 \mu \mathrm{m}$. Figure 25-26.
Geographic distribution in the Paraná State: Lozovei \& Luz (1976); Lozovei \& Hohmann (1977); Cecy et al. (1997); Cetto et al. (2004); Silva \& Cecy (2004); Bortolini et al. (2010b); Menezes et al. (2011b); Aquino et al. (2014, 2016).

Frequency of occurrence: Rare

Cosmarium obsoletum (Hantzsch) Reinsch var. obsoletum, Acta Soc. Senckenberg, 6: 142, pl. 22D1, fig. 1-4. 1867.

Basionym: Arthrodesmus obsoletus Hantzsch in Rabenhorst, Algen Europa's. no 1407. 1862

Cells 1.1 times wider than long. Semicells semicircular with rounded margins and slightly truncated apex. Cell wall smooth. Median constriction deep with closed linear sinus, slightly open at the extremities. Chloroplast axial. Pyrenoids 2 per semicell. L: $43.1 \mu \mathrm{m}$; W: $48.5 \mu \mathrm{m}$; I: $17 \mu \mathrm{m}$. Figure 27.

Geographic distribution in the Paraná State: Aquino et al. (2016).

Frequency of occurrence: Rare

Cosmarium pseudoconnatum Nordstedt var. pseudoconnatum, Vidensk. Medd. Naturh. For. Kjöbenhavn, 21: 214, pl. 3, fig. 17. 1870.

Cells 1.2-1.3 times longer than wide. Semicells semicircular with rounded-oval outline and smooth margins. Apex rounded. Cell wall finely punctuated. Median constriction shallow. Median sinus open. Chloroplast axial, radiate. Pyrenoids 2 per semicell. L: 41.9-60 $\mu \mathrm{m}$; W: 31-49.4 $\mu \mathrm{m}$; I: $25-55 \mu \mathrm{m}$. Figure 28-29.

Geographic distribution in the Paraná State: Bittencourt-Oliveira (1993); Cecy et al. (1997); Picelli-Vicentim et al. (2001); Silva \& Cecy (2004); Felisberto \& Rodrigues (2005a, 2008); Bortolini et al. (2010b); Menezes et al. (2011b); Aquino et al. (2014).

Frequency of occurrence: Common

Cosmarium pseudopyramidatum P. Lundell var. excavatum (Nordstedt) Krieger \& Gerloff, Die Gattung Cosmarium, Lief 2:127, taf 26, fig.7. 1965.

Basionym: Cosmarium pseudopyramidatum P. Lundell f. excavata Nordstedt., Acta Univ. Lund., 19: 13.1873.

Cells 1.6 times longer than wide. Semicells pyramidal-truncated, basal angles obliquely rounded; lateral margins widely concave, convergent towards the apex. Apex truncated or rounded. Cell wall punctate. Median constriction deep. Linear sinus closed. Chloroplast axial. Pyrenoids not observed. L: 62.5-75.3 $\mu \mathrm{m}$; W: 37.5-45.7 $\mu \mathrm{m}$; I: $16.5-19.9 \mu \mathrm{m}$. Figure 30 . 
Geographic distribution in the Paraná State: First record of the taxon.

Frequency of occurrence: Sporadic

Cosmarium quadrum P. Lundell var. minus Nordstedt, Lund. Univ. Arsskr., 9 (10): 11. 1873.

Cells slightly wider than long. Semicells subrectangular with lateral and apical margins undulate, slightly convex and straight. Apex retuse to straight. Cell wall ornamented with warts arranged in vertical rows, following the cell's outline. Median constriction deep. Linear median sinus closed, with dilated at the extremities. Chloroplast axial. Pyrenoids 2 per semicell. L: 37.3-39.2 $\mu \mathrm{m}$; W: 39.6-40.7 $\mu \mathrm{m}$; I: 12.4-12.5 $\mu \mathrm{m}$. Figure 31 .

Geographic distribution in the Paraná State: Felisberto \& Rodrigues (2005a, b, 2012); Bortolini et al. (2010b); Menezes et al. (2011b); Aquino et al. (2014, 2016).

Frequency of occurrence: Sporadic

Cosmarium subspeciosum Nordstedt var. subspeciosum, Öfv., Kongl. Vet. -Akad. Förhandl., 32(6): 22, pl. 6, fig. 13. 1875.

Cells 1.3-1.4 times longer than wide. Semicells semicircular to pyramidal, with crenulate margins. Apex truncated-rounded, granulate. Cell wall densely granulate; granules in radial series toward the cellular center, median region with some angles. Median constriction deep. Linear median sinus closed. Chloroplast axial. Pyrenoids 2 per semicell. L: 43.8-49 $\mu \mathrm{m}$; W: 30-35.8 $\mu \mathrm{m}$; I: 10.1-13.3 $\mu \mathrm{m}$. Figure 32.

Geographic distribution in the Paraná State: Felisberto \& Rodrigues (2005a, 2008); Bortolini et al. (2010a); Menezes et al. (2011b); Aquino et al. (2014, 2016).

Frequency of occurrence: Sporadic

Cosmarium subspeciosum Nordstedt var. validius Nordstedt, K. Svenska Vet. -Akad. Handl., 22 (8): 49, pl. 5, fig. 10. 1888.

Cel 1.4 times longer than wide. Semicells pyramidal-truncated with lateral and apical margins with prominent crenulations, and truncate-rounded apex. Cell wall granulate, granules in radial series forming lines toward the region center, central protuberance with vertical lines of granules. Median constriction deep. Linear median sinus closed. Basal angles abruptly rounded. Chloroplast axial. Pyrenoids 2. L: 77.5-92 $\mu \mathrm{m}$; W: 52.5-62.5 $\mu \mathrm{m}$; I: $17-19.4 \mu \mathrm{m}$. Figure 33.

Geographic distribution in the Paraná State: Silva \& Cecy (2004); Felisberto \& Rodrigues (2005a, 2008); Bortolini et al. (2010b); Aquino et al. (2014).

Frequency of occurrence: Sporadic
Cosmarium trilobulatum Reinsch var. trilobulatum, Acta Soc. Senckenberg, 6: 118(10), pl. 22(3) A II, fig. 1-6. 1867.

Cell 1.1-1.2 times longer than wide. Semicell subtrapeziform, 3-lobed with slightly convex lateral margins. Apex wide, truncated. Cell wall smooth or finely punctate. Median constriction deep, with linear sinus closed. Chloroplast axial. Pyrenoids 1 per semicell. L: $25.8-27.6 \mu \mathrm{m}$; W: $20.5-28 \mu \mathrm{m}$; I: $7.8-10 \mu \mathrm{m}$. Figure 34 .

Geographic distribution in the Paraná State: Felisberto \& Rodrigues (2005a, b, 2010a, 2012); Algarte et al. (2006); Biolo \& Rodrigues (2011); Aquino et al. (2014).

Frequency of occurrence: Sporadic

Desmidium grevillei (Kützing ex Ralfs) De Bary, Ein Beit. phys. besch. Botanik., 76, pl. 4, fig. 30-31. 1858.

Basionym: Didymoprium grevillea Kützing ex Ralfs 57, pl. 2. 1848.

Cell 2.1-2.3 times wider than long. Semicells oblong with rounded lateral margins. Filament not twisted. Cell wall smooth. Median constriction shallow. Sinus open. Chloroplast axial. Pyrenoids not observed. L: 17.5-22.9 $\mu \mathrm{m}$; W: 41.2-48.2 $\mu \mathrm{m}$; I: $40-47 \mu \mathrm{m}$. Figure 35 .

Geographic distribution in the Paraná State: Bittencourt-Oliveira (1993); Bortolini et al. (2008); Felisberto \& Rodrigues (2010b); Menezes et al. (2011a, 2013).

Frequency of occurrence: Common

Identification key for the taxa recorded in the genus Euastrum

1. Face of semicell ornamented with 3 mucilage pores Euastrum sp.

1. Face of semicell without mucilage pores Euastrum bidentatum var. bidentatum

Euastrum bidentatum Nägeli var. bidentatum, Gatt. Einz. Algen, 122, pl. 7D, fig. 1a-f. 1849.

Cell 1.3-1.4 times longer than wide. Semicells semi-elliptical. Apical margin truncated-rounded, angular and with a wide $\mathrm{V}$-shaped incision, ornamented with a spine-like process. Median constriction deep, with closed linear sinus. Face of semicell ornamented with several granules. Chloroplast axial. Pyrenoids 1 per semicell. L: 47.1-47.2 $\mu \mathrm{m}$; W: 33.2-34.9 $\mu \mathrm{m}$; I: 7.5-7.8 $\mu \mathrm{m}$. Figure 36-37.

Geographic distribution in the Paraná State: First record of the taxon.

Frequency of occurrence: Sporadic

Euastrum sp. 
Cell 2 times longer than wide. Semicells semi-elliptical. Apical margin truncated with a wide incision. Median constriction deep, linear sinus closed.
Face of semicell ornamented with 3 mucilage pores. Chloroplast axial. Pyrenoids 1 per semicell. L: 61.4-90 $\mu \mathrm{m}$; W: 30.5-44.3 $\mu \mathrm{m}$; I: 10.1-15 $\mu \mathrm{m}$. Figure 38-39.
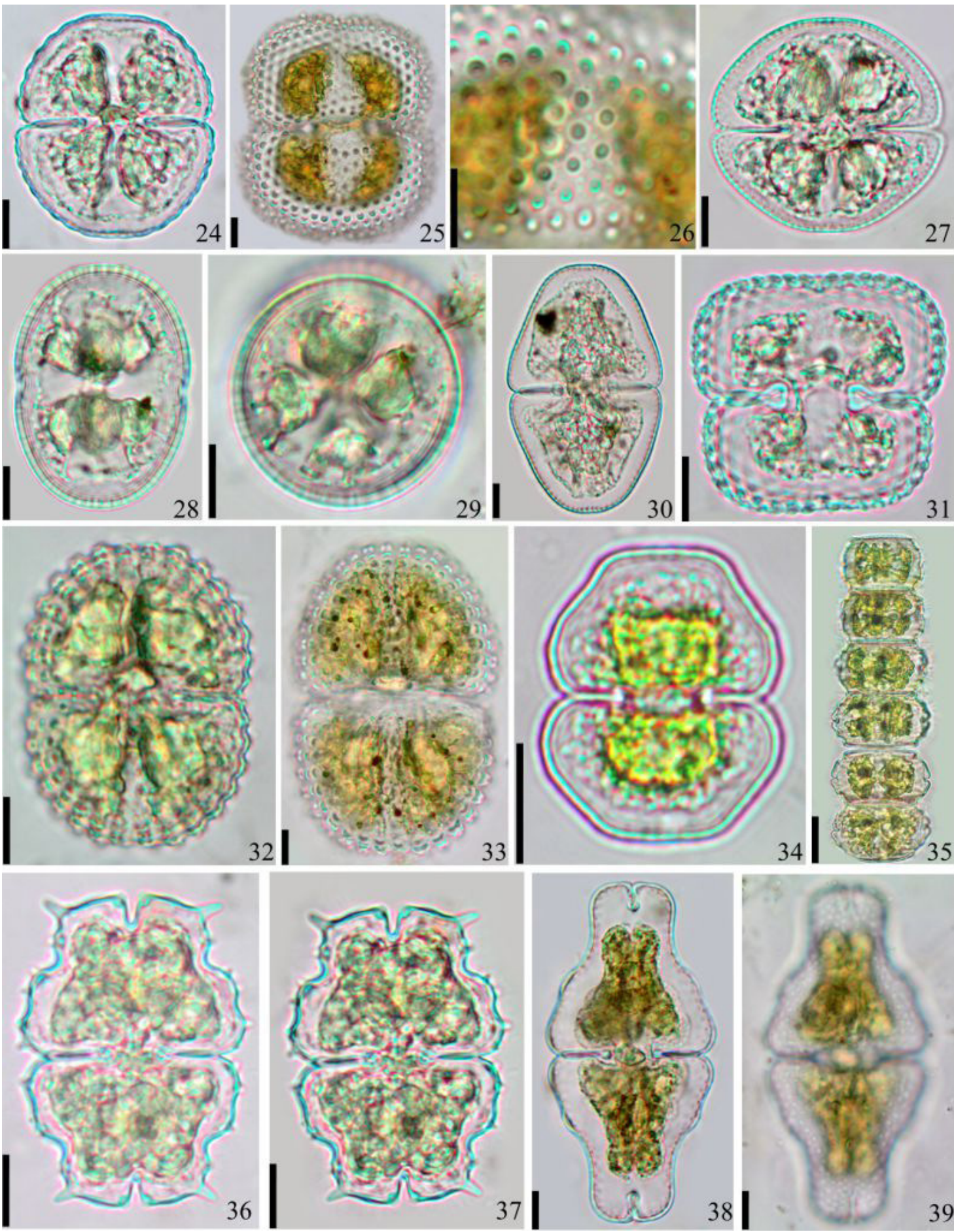

iserions

है।

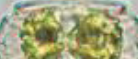

soseses

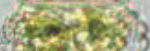

34

Figure 24-39. Desmids of the Cascavel municipal lake, Paraná, Brazil. 24. Cosmarium dispersum f. dispersum 25-26. C. margaritatum var. margaritatum f. margaritatum 26. Detail of the cell wall 27. C. obsoletum var. obsoletum 28-29. C. pseudoconnatum var. pseudoconnatum 29. Apical view 30. C. pseudopyramidatum var. excavatum 31. C. quadrum var. minus. 32. C. subspeciosum var. subspeciosum 33. C. subspeciosum var. validius 34. C. trilobulatum var. trilobulatum 35. Desmidium grevillei 36-37. Euastrum bidentatum var. bidentatum 37. Detail of the cell wall 38-39. Euastrum sp. 39. Detail of the cell wall. Scale $10 \mu \mathrm{m}$. 
Geographic distribution in the Paraná State: First record of the taxon.

Frequency of occurrence: Sporadic

Identification key for the taxa recorded in the genus Micrasterias

1. Semicells 3-lobed.................Micrasterias laticeps var. laticeps

1. Semicells 5-lobed . .2

2. Cell wall punctuated Micrasterias quadridentata

2. Cell wall ornamented with short spines ..Micrasterias borgei var. borgei

Micrasterias borgei Krieger var. borgei in Rabenhorst Kryptogamen-Fl. Deutschl., 13 (2): 86, pl.128, fig. 1-4. 1939.

Cells 1.0-1.1 times longer than wide. Semicells elliptic to elliptical-oblong, 5-lobed, with acutangular interlobular incisions. Apical lobe long, narrow, extending slightly besides the lateral lobes. Cell wall ornamented with short spines. Median constriction deep. Linear sinus closed, slightly open at the extremities. Lateral and basal lobes separated by a linear incision, acutangular at the distal portion. Basal lobes subdivided in 2-4 lobules, acutangular, 2-4 denticulate. Lateral lobes subdivided in 4-8 lobules, acutangular. Chloroplast axial. Numerous pyrenoids. L: 235-265.7 $\mu \mathrm{m}$; W: $214.8-230 \mu \mathrm{m}$; I: 29.6-47.5 $\mu \mathrm{m}$. Figure 40-42.

Geographic distribution in the Paraná State: Bittencourt-Oliveira \& Mecenas (1994); Algarte et al. (2006); Felisberto \& Rodrigues (2005a, 2011); Moresco et al. (2009); Menezes et al. (2011a).

Frequency of occurrence: Common

Micrasterias laticeps Nordstedt var. laticeps, Vidensk. Meddr Naturh. Foren., (1869), 14-15: 220. 1870.

Cells 1.2-1.3 times wider than long or 1.0 times longer than wide. Semicells elliptic, 3-lobed with superior margin convex to straight in the median portion. Apical lobe fusiform to subcuneiform. Interlobular incisions acutangular. Cell wall finely punctuated. Median constriction deep. Basal lobe semifusiform, with 2-denticulated extremities. Chloroplast axial. Multiple pyrenoids. L: $110-176.8 \mu \mathrm{m}$; W: 127.6-227.6 $\mu \mathrm{m}$; I: $20.8-40.3 \mu \mathrm{m}$. Figure 43-44.

Geographic distribution in the Paraná State: Andrade \& Rachou (1954); Lozovei \& Hohmann (1977); Picelli-Vicentim (1984); Bittencourt-Oliveira \& Mecenas (1994); Bittencourt-Oliveira (2002); Felisberto \& Rodrigues (2005a, 2008, 2010b, 2011); Biolo et al. (2008).

Frequency of occurrence: Sporadic
Micrasterias quadridentata (Nordstedt) Grönblad, Acta Soc. Fauna Flora Fenn., 47(4): 36. 1920.

Cell 1.1-1.2 times longer than wide. Semicell circular, 5-lobed. Interlobular incisions linear, narrow. Apical lobe long, narrow, not extending besides the lateral lobes, margins straight or slightly concave, opening to the beveled apex. Angles acuminate or 2-denticulated. Cell wall punctuated. Median constriction deep. Sinus linear. Basal and lateral lobes subdivided in 4 lobules by 3 incisions. Apex of lobules truncated, sometimes beveled in the median portion, angles with 1 denticle. Chloroplast axial. Multiple pyrenoids. L: 271.3-465 $\mu \mathrm{m}$; W: 229-374.7 $\mu \mathrm{m}$; I: 33.1-60 $\mu \mathrm{m}$. Figure 45.

Geographic distribution in the Paraná State: Moresco et al. (2009); Menezes et al. (2011a).

Frequency of occurrence: Common

Identification key for the taxa recorded for the genus Netrium

1. Chloroplast with lamellae and lateral projections..............Netrium digitus var. lamellosum

1. Chloroplast without lamellae or projections.....................Netrium digitus var. digitus

Netrium digitus (Ralfs) Itzigsohn \& Rothe var. digitus in Rabenhorst, Alg. Sachsen, 508. 1856.

Basionym: Penium digitus Ralfs, Brit. Desmidieae. 150, pl. 25, fig. 3. 1848

Cells 3-4 times longer than wide. Cells oblong-elliptical, with lateral margins slightly convex. Apex truncated-rounded. Cell wall smooth. Chloroplast axial with denticulate projections. Pyrenoids 2-3, longitudinally distributed. L: 121.9-266.4 $\mu \mathrm{m}$; W: 39.1-67.5 $\mu \mathrm{m}$. Figure 46.

Geographic distribution in the Paraná State: Felisberto \& Rodrigues (2008); Bortolini et al. (2010a).

Frequency of occurrence: Sporadic

Netrium digitus (Ehrenberg ex Ralfs) Itzigsohn \& Rothe var. lamellosum (Brébisson) Grönblad, Acta Soc. Fauna Flora Fenn., 47(4): 13. 1920.

Basionym: Penium lamellosum Bréb., Mém. Soc. Sci. Nat. Cherbourg 4: 146, pl. 2, fig. 34. 1856.

Cells 5-6 times longer than wide. Cells narrow, elliptical-elongate, with lateral subparallel margins. Apex rounded. Cell wall smooth. Median constriction shallow. Chloroplast axial, with prominent lateral projections. Pyrenoids 2-3, arranged in the median region of the chloroplast. L: $270.5-342.7 \mu \mathrm{m}$; W: $49-51.8 \mu \mathrm{m}$. Figure 47.

Geographic distribution in the Paraná State: Felisberto \& Rodrigues (2008). 
Frequency of occurrence: Sporadic

Identification key for the taxa recorded in the genus Penium

1. Cell wall with longitudinal spiral striae of uneven spaced granules ......Penium spirostriolatum

1. Cell wall with longitudinal irregular lines of small granules..................Penium margaritaceum var. margaritaceum

Penium margaritaceum (Ehrenberg) Brébisson ex Ralfs var. margaritaceum, Brit. Desm., 149, pl. 25, fig. 3; pl. 33, fig. 1. 1848.

Basionym: Closterium margaritaceum Ehrenberg, 95, pl. 6, fig. 13. 1838.

Cell 4-5 times longer than wide. Semicells elongate-cylindrical, with parallel margins. Apex subtruncated-rounded. Cell wall red-brownish, ornamented with longitudinal irregular lines of small granules; presence of elongation zones. Pyrenoids 1, spherical and central in each branch. L: 95.5-132 $\mu \mathrm{m}$; W: 20.2-22.1 $\mu \mathrm{m}$. Figure 48-49.

Geographic distribution in the Paraná State: Felisberto \& Rodrigues (2005a, 2010b); Biolo et al. (2008); Aquino et al. (2014).

Frequency of occurrence: Sporadic

Penium spirostriolatum J. Barker, Quart. J. Microscop. Sci., series 2, 9: 194. 1869.

Cell 6 times longer than wide. Semicells cylindrical and elongate. Apex truncated-rounded. Cell wall brownish, ornamented with longitudinal spiral striae of uneven spaced granules; presence of several constrictions along the cell. Median constriction shallow or little apparent. Chloroplast 2-4 per cell, each one with 5-7 longitudinal rings. Pyrenoids central, spherical to slightly elongate in each branch. L: $125.7 \mu \mathrm{m}$, W: $18.9 \mu \mathrm{m}$. Figure 50 .

Geographic distribution in the Paraná State: First record of the taxon.

Frequency of occurrence: Rare

Pleurotaenium trabecula (Ehrenberg) Nägeli var. trabecula f. trabecula, Gatt. Einzell. Alg., 104, pl.6, fig. A. 1849.

Basionym: Closterium trabecula Ehrenberg, Infusoria, 62: 70. 1830.

Cell 9-15 times longer than wide. Semicells cylindrical with lateral margins parallel; 1 basal intumescence, 1-2 light undulations above the intumescence; rounded angles. Apical margin retuse, smooth and with subquadratic angles. Cell wall hyaline, punctuated. Median constriction shallow. Median sinus open. Chloroplast parietal, in the form of a longitudinal band. Several pyrenoids per chloroplast. L: 533-561 $\mu \mathrm{m}$, W: 34.6-60 $\mu \mathrm{m}$; I: $28.6-40 \mu \mathrm{m}$. Figure 51.
Geographic distribution in the Paraná State: Cetto et al. (2004); Bortolini et al. (2008); Aquino et al. (2014).

Frequency of occurrence: Sporadic

Staurastrum alternans Brébisson ex Ralfs var. alternans, Brit. Desm., 132, pl. 21, fig. 7. 1848.

Cell 1.2 times longer than wide. Semicell triangular, oblong with rounded angles. Short process. Apex flattened, truncated. Cell wall granulated. Median constriction deep. Sinus open. Chloroplast axial. Pyrenoids 1 per semicell. L: 23.2-26.7 $\mu \mathrm{m}$; W: $18-21.8 \mu \mathrm{m}$; I: 8.4-8.9 $\mu \mathrm{m}$. Figure 52-53.

Geographic distribution in the Paraná State: Bittencourt-Oliveira \& Mecenas (1994); Felisberto \& Rodrigues $(2008,2013)$.

Frequency of occurrence: Common

In this study, even though we did not attempt to make any quantitative estimation, a decrease in the number of taxa was recognized throughout the analyzed period. The greatest number of taxa was recorded in 2015, when 33 taxa occurred in the epilithic substrate and 18 taxa in the epiphytic substrate, while in 2016 and 2017 the number of taxa recorded in both substrates was smaller (17 and 5, respectively). Among the taxa recorded, nine were exclusive to the epilithic substrate and only Netrium digitus (Ralfs) Itzigsohn \& Rothe var. digitus was recovered from the epiphytic substrate, whereas the other 25 taxa occurred on both substrates (Table 3). The presence of natural substrates potentially influences the desmids, whose development depends on the type of substrates available (Coesel, 1982; Barbosa et al., 2013). Among the taxa recorded, seven are new records for the Paraná State: Actinotaenium cucurbitinum var. cucurbitinum (Bisset) Teiling f. minus, Closterium acerosum (Schrank) Ehrenberg var. acerosum, Closterium braunii Reinsch, Cosmarium pseudopyramidatum P. Lundel var. excavatum Börgesen, Euastrum bidentatum Nägeli var. bidentatum, Euastrum sp. and Penium spirostriolatum J. Barke.

The genera Cosmarium (12 taxa) and Closterium (10 taxa) presented the greatest number of taxa. These genera are cosmopolitan and exhibit high diversity in different environmental scenarios (Coesel, 1996), being common in oligotrophic and mesotrophic aquatic systems (Graham \& Wilcox, 2000). Members of Cosmarium are ubiquitous and have developed numerous protective strategies (e.g. low number of thylakoids per granum, long and exposed stroma lamellae, 
numerous and moderately large plastoglobules and large starch grains) to survive higher temperature conditions at various latitudes and altitudes (Stamenkovič \& Hanelt, 2017). Regarding the frequency of occurrence, most taxa were sporadic, followed by common and
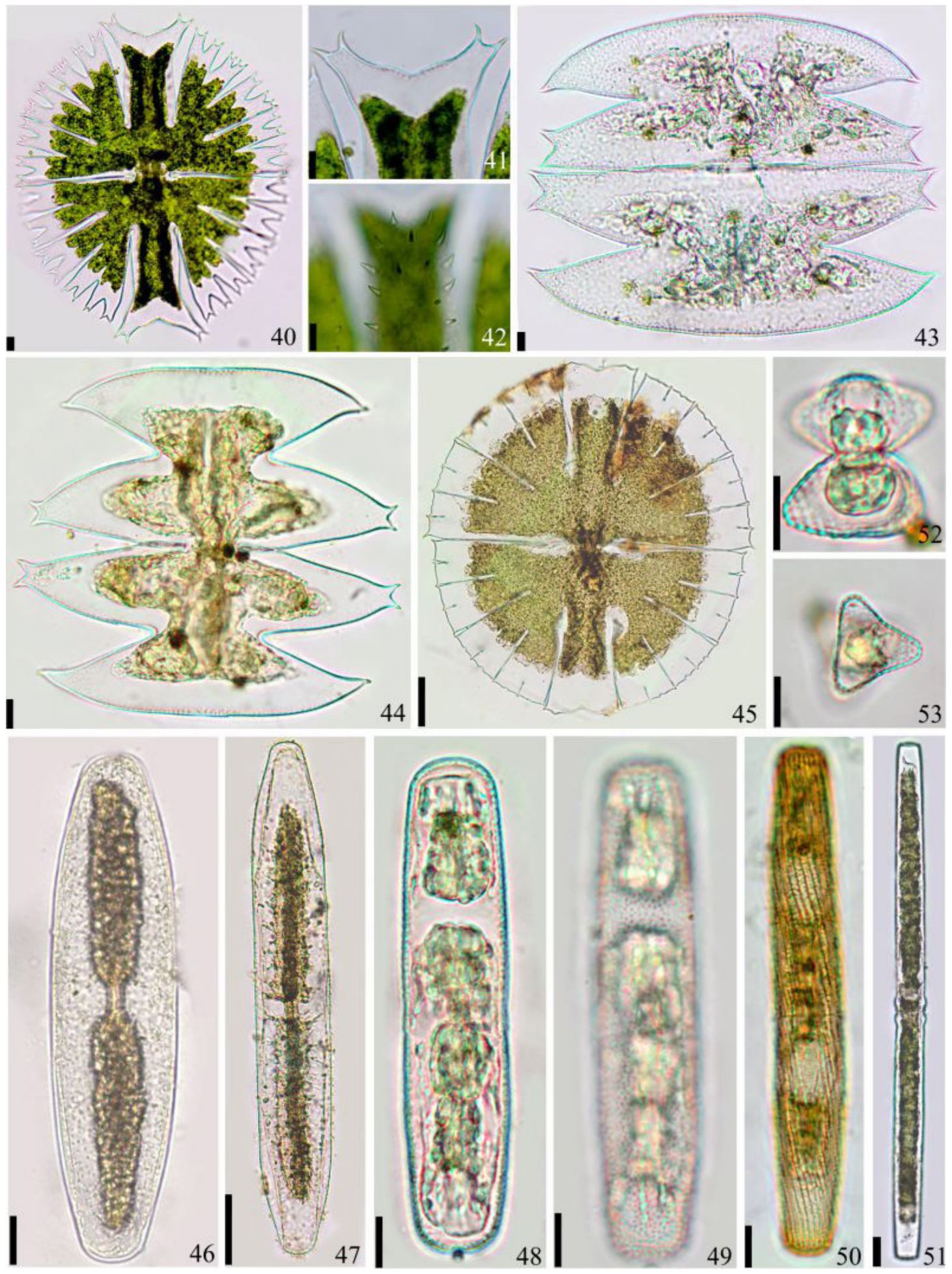

Figure 40-53. Desmids of the Cascavel municipal lake, Paraná, Brazil. 40-42. Micrasterias borgei var. borgei 41. Detail of the Apex 42. Detail of the cell wall 43-44. M. laticeps var. laticeps 45. M. quadridentata 46. Netrium digitus var. digitus 47. $N$. digitus var. lamellosum 48-49. Penium margaritaceum var. margaritaceum 49. Detail of the cell wall 50. P. spirostriolatum 51. Pleurotaenium trabecula var. trabecula f. trabecula 52-53. Staurastrum alternans var. alternans 53. Apical view. Scale $10 \mu \mathrm{m}$. 
rare taxa, while no constant taxa were recorded (Table 3). Cosmarium pseudoconnatum Nordstedt var. pseudoconnatum and Desmidium grevillei (Kützing ex Ralfs) De Bary were the taxa with the greatest occurrence $(58 \%$ in both cases).
Although the results obtained in the present study are of qualitative nature, they provide baseline data on the biogeographic distribution of taxa in continental aquatic environments. Desmids are considered as excellent indicators of water quality

Table 3. List of occurrence of the periphytic desmids taxa in the Cascavel municipal lake in different substrates (EP - epilithon; EF - epiphyton), in the sampling performed in 2015, 2016 and 2017 (FO - frequency of occurrence, C - Common, S - Sporadic, R - Rare). Emphasizing the occurence ( $\bullet$ ) or absence (-) of taxa.

\begin{tabular}{|c|c|c|c|c|c|c|c|c|}
\hline \multirow{2}{*}{ Taxa } & \multicolumn{2}{|c|}{2015} & \multicolumn{2}{|c|}{2016} & \multicolumn{2}{|c|}{2017} & \multirow{2}{*}{ FO } & \multirow{2}{*}{$\begin{array}{c}\text { Voucher } \\
\text { UNOP-Algae }\end{array}$} \\
\hline & EP & EF & EP & EF & EP & EF & & \\
\hline $\begin{array}{l}\text { Actinotaenium cucurbitinum var. cucurbitinum } \\
\text { (Bisset) Teiling f. minus (West \& G.S. West) Teiling }\end{array}$ & $\bullet$ & $\bullet$ & - & $\bullet$ & - & - & $\mathrm{C}$ & $2615,2616,4186,4187,4188$ \\
\hline $\begin{array}{l}\text { Closterium acerosum Ehrenberg ex Ralfs var. } \\
\text { acerosum }\end{array}$ & $\bullet$ & $\bullet$ & - & - & - & - & S & $4185,4187,4188$ \\
\hline $\begin{array}{l}\text { C. baillyanum (Brébisson ex Ralfs) Brébisson var. } \\
\text { baillyanum }\end{array}$ & $\bullet$ & $\bullet$ & - & - & - & - & $S$ & $4185,4186,4188$ \\
\hline C. braunii Reinsch & $\bullet$ & & - & - & - & - & $\mathrm{R}$ & 4187 \\
\hline $\begin{array}{l}\text { C. closterioides (Ralfs) A. Louis \& Peeters var. } \\
\text { closterioides }\end{array}$ & $\bullet$ & $\bullet$ & - & - & - & - & S & 4186,4188 \\
\hline C. incurvum Brébisson var. incurvum & $\bullet$ & $\bullet$ & - & $\bullet$ & - & - & $\mathrm{C}$ & $4185,4186,4188,2615,2616$ \\
\hline C. kuetzingii Brébisson var. kuetzingii & $\bullet$ & - & - & $\bullet$ & - & - & $\mathrm{C}$ & $2616,4186,4187,4188$ \\
\hline C. malmei Borge var. malmei & - & $\bullet$ & - & - & - & - & S & 4185,4188 \\
\hline C. navicula (Brébisson) J. Lütkemüller var. navicula & $\bullet$ & $\bullet$ & $\bullet$ & $\bullet$ & - & - & $\mathrm{C}$ & $2615,2616,2618,4185,4188$ \\
\hline C. pseudolunula Borge var. pseudolunula & $\bullet$ & - & - & - & - & - & S & 4187,4188 \\
\hline C. tumidum L.N. Johnson var. tumidum & - & - & $\bullet$ & - & - & - & S & 2617,2618 \\
\hline Cosmarium candianum Delponte var. candianum & $\bullet$ & $\bullet$ & - & - & - & - & S & $4186,4187,4188$ \\
\hline C. decoratum West \& G.S. West & $\bullet$ & $\bullet$ & - & - & - & - & S & $4185,4186,4188$ \\
\hline C. denticulatum Borge var. ovale Grönblad & $\bullet$ & - & - & - & - & - & $\mathrm{R}$ & 4188 \\
\hline $\begin{array}{l}\text { C. dispersum L.N. Johnson f. dispersum L.N. } \\
\text { Johnson }\end{array}$ & $\bullet$ & - & - & $\bullet$ & - & - & $\mathrm{S}$ & 2615,4188 \\
\hline $\begin{array}{l}\text { C. margaritatum (P. Lundell) Roy \& Bisset var. } \\
\text { margaritatum f. margaritatum }\end{array}$ & $\bullet$ & - & - & - & - & - & $\mathrm{R}$ & 4188 \\
\hline C. obsoletum (Hantzch) Reinsch var. obsoletum & $\bullet$ & - & - & - & - & - & $\mathrm{R}$ & 4188 \\
\hline $\begin{array}{l}\text { C. pseudoconnatum Nordstedt var. } \\
\text { pseudoconnatum }\end{array}$ & $\bullet$ & $\bullet$ & $\bullet$ & $\bullet$ & - & - & C & $\begin{array}{l}2615,2616,2618,4185,4186 \\
4187,4188\end{array}$ \\
\hline $\begin{array}{l}\text { C. pseudopyramidatum P. Lundell var. excavatum } \\
\text { (Nordstedt) Krieger \& Gerloff }\end{array}$ & - & $\bullet$ & - & - & - & - & $\mathrm{S}$ & $4185,4186,4188$ \\
\hline C. quadrum Lundell var. minus Nordstedt & - & - & - & - & - & $\bullet$ & $\mathrm{S}$ & $4187,4188,4493$ \\
\hline C. subspeciosum Nordstedt. var. subspeciosum & $\bullet$ & - & - & $\bullet$ & - & - & S & $2615,2616,4188$ \\
\hline C. subspeciosum Nordstedt.var. validius Nordstedt & $\bullet$ & $\bullet$ & - & - & - & - & S & 4186,4188 \\
\hline C. trilobulatum Reinsch var. trilobulatum & $\bullet$ & - & - & $\bullet$ & - & - & S & $2615,2616,4188$ \\
\hline Desmidium grevillei (Kützing ex Ralfs) De Bary & $\bullet$ & - & $\bullet$ & $\bullet$ & $\bullet$ & $\bullet$ & $\mathrm{C}$ & $\begin{array}{l}2617,4185,4186,4187,4188, \\
4491,4492\end{array}$ \\
\hline Euastrum bidentatum Nägeli var. bidentatum & $\bullet$ & - & - & - & - & - & S & 4187,4188 \\
\hline Euastrum sp. & $\bullet$ & $\bullet$ & - & - & - & - & S & $4186,4187,4188$ \\
\hline Micrasterias borgei Krieger var. borgei & $\bullet$ & $\bullet$ & - & - & $\bullet$ & - & $\mathrm{C}$ & $4185,4186,4188,4491$ \\
\hline M. laticeps Nordstedt var. laticeps & $\bullet$ & - & - & - & - & - & $\mathrm{S}$ & 4187,4188 \\
\hline M. quadridentata (Nordstedt) Gronblad & $\bullet$ & $\bullet$ & - & - & $\bullet$ & - & $\mathrm{C}$ & $4185,4187,4188,4491$ \\
\hline $\begin{array}{l}\text { Netrium digitus (Ralfs) Itzigsohn \& Rothe var. } \\
\text { digitus }\end{array}$ & - & $\bullet$ & - & $\bullet$ & - & - & $S$ & $2615,4185,4186$ \\
\hline $\begin{array}{l}\text { N. digitus (Ehrenberg ex Ralfs) Itzigsohn \& Rothe } \\
\text { var. lamellosum (Brébisson) Grönblad }\end{array}$ & $\bullet$ & $\bullet$ & - & - & - & - & $\mathrm{S}$ & $4185,4186,4188$ \\
\hline $\begin{array}{l}\text { Penium margaritaceum (Ehrenberg) Brébisson ex } \\
\text { Ralfs var. margaritaceum }\end{array}$ & $\bullet$ & - & - & $\bullet$ & - & - & $S$ & $2615,2616,4188$ \\
\hline P. spirostriolatum J. Barker & $\bullet$ & - & - & - & - & - & $\mathrm{R}$ & 4188 \\
\hline $\begin{array}{l}\text { Pleurotaenium trabecula (Ehrenberg) Nägeli var. } \\
\text { trabecula f. trabecula }\end{array}$ & - & $\bullet$ & - & - & - & - & $S$ & $4186,4187,4188$ \\
\hline $\begin{array}{l}\text { Staurastrum alternans Brébisson ex Ralfs var. } \\
\text { alternans }\end{array}$ & $\bullet$ & - & $\bullet$ & $\bullet$ & - & - & C & $2615,2616,2618,4187$ \\
\hline
\end{tabular}


because they are highly sensitive to changes in the environmental conditions. Therefore, studies of this nature are of great importance for the monitoring of aquatic ecosystems, once the local and regional biodiversity knowledge provides the base to propose measures of preservation and conservation of the biodiversity.

\section{Acknowledgements}

We thank the Fundação Araucária de Apoio ao Desenvolvimento Científico e Tecnológico do Paraná and Coordenação de Aperfeiçoamento de Pessoal de Nível Superior - CAPES for providing scholarship to CANA, GM and CCRF and Conselho Nacional de Pesquisa e Desenvolvimento - CNPq for providing post-doctoral scholarship to JCB (process 165796/2015-4) and Research Productivity Grant to NCB (process 307196/2013-5).

\section{References}

ALGARTE, V.M., MORESCO, C. and RODRIGUES, L. Algas do perifíton de distintos ambientes na planície de inundação do alto Rio Paraná. Acta Scientiarum. Biological Sciences, 2006, 28(3), $243-$ 251.

ALVARES, C.A., STAPE, J.L., SENTELHAS, P.C., GONÇALVES, J.L.M. and SPAROVEK, G. Köppen's climate classification map for Brazil. Meteorologische Zeitschrift, 2014, 22(6), 711-728. http://dx.doi.org/10.1127/0941-2948/2013/0507.

ANDRADE, R.M. and RACHOU, R.G. Levantamento preliminar de organismos planctônicos em alguns criadouros do Anopheles darlingi no sul do Brasil. Revista Brasileira de Malariologia e Doenças Tropicais, 1954, 6, 481-496.

AQUINO, C.A.N., BUENO, N.C. and MENEZES, V.C. Desmidioflórula (Zygnemaphyceae, Desmidiales) do rio Cascavel, Oeste do Estado do Paraná, Brasil. Hoehnea, 2014, 41(3), 365-392. http://dx.doi. org/10.1590/S2236-89062014000300005.

AQUINO, C.A.N., BUENO, N.C., SERVAT, L.C. and BORTOLINI, J.C. New records of Cosmarium Corda ex Ralfs in lotic environment, adjacent to the Iguaçu National Park, Paraná State, Brazil. Hoehnea, 2016, 43(4), 669-688. http://dx.doi. org/10.1590/2236-8906-54/2016.

BARBOSA, L.G., BARBOSA, F.A.R. and BICUDO, C.E.M. Adaptive strategies of desmids in two tropical monomictic lakes in southeast Brazil: do morphometric differences promote life strategies selection? Hydrobiologia, 2013, 710(1), 157-171. http://dx.doi.org/10.1007/s10750-013-1458-0.

BICUDO, C.E.M. and MENEZES, M. Gêneros de algas de águas continentais do Brasil: chave para identificação e descriçóes. São Carlos: RiMa, 2006.
BIOLO, S. and RODRIGUES, L. Composição de algas perifíticas (exceto Bacillariophyceae) em distintos substratos naturais de um ambiente semilótico, planície de inundação do Alto Rio Paraná, Brasil. Revista Brasileira de Botanica. Brazilian Journal of Botany, 2011, 34(3), 307-319. http://dx.doi. org/10.1590/S0100-84042011000300006.

BIOLO, S., BUENO, N.C., SIQUEIRA, N.S. and MORESCO, C. New records of Cosmarium Corda ex Ralfs (Desmidiaceae, Zygnematophyceae) in a tributary of the Itaipu Reservoir, Paraná, Brazil. Acta Botanica Brasílica, 2013, 27(1), 1-12. http://dx.doi. org/10.1590/S0102-33062013000100001.

BIOLO, S., SIQUEIRA, N.S. and BUENO, N.C. Desmidiaceae (exceto Cosmarium) de um tributário do Reservatório de Itaipu, Paraná, Brasil. Hoehnea, 2008, 35(2), 145-162. http://dx.doi.org/10.1590/ S2236-89062008000200012.

BITTENCOURT-OLIVEIRA, M.C. Ficoflórula do Rio Tibagi, Estado do Paraná, Brasil III: gêneros Actinotaenium, Cosmarium e Staurodesmus (Zygnemaphyceae). Semina, 1993, 149(2), 86-95.

BITTENCOURT-OLIVEIRA, M.C. A comunidade fitoplanctônica do rio Tibagi: uma abordagem preliminar de sua diversidade. In: M.M. MEDRI, E. BIANCHINI, O.A. SHIBATTA and J.A. PIMENTA, eds. A Bacia do rio Tibagi. Londrina: FUEL, 2002.

BITTENCOURT-OLIVEIRA, M.C. and CASTRO, A.A.J. Ficoflórula do Rio Tibagi, Estado do Paraná, Brasil, II: gênero Closterium (Zygnemaphyceae). Semina, 1993, 149(2), 74-85.

BITTENCOURT-OLIVEIRA, M.C. and MECENAS, P.R. Ficoflórula do Rio Tibagi, Estado do Paraná, Brasil, IV: gêneros Micrasterias, Staurastrum e Xanthidium (Zygnemaphyceae). Semina, 1994, 15(2), 133-152.

BORTOLINI, J.C., BUENO, N.C., MORESCO, C., BIOLO, S. and SIQUEIRA, N.S. Cosmarium Corda ex Ralfs (Desmidiaceae) em um lago artificial urbano, Paraná, Brasil. Revista Brasileira de Biociências, 2010b, 38(3), 229-237.

BORTOLINI, J.C., MEURER, T. and BUENO, N.C. Desmídias (Zygnemaphyceae) do Rio São João, Parque Nacional do Iguaçu, Paraná, Brasil. Hoehnea, 2010a, 37(2), 293-313. http://dx.doi.org/10.1590/ S2236-89062010000200005.

BORTOLINI, J.C., MORESCO, C., SIQUEIRA, N.S., BIOLO, S. and BUENO, N.C. Closterium Nitzsch ex Ralfs (Desmidiaceae) em um lago artificial urbano, Paraná, Brasil. Hoehnea, 2009, 36(3), 445-454. http://dx.doi.org/10.1590/S223689062009000300006 .

BORTOLINI, J.C., MORESCO, C., SIQUEIRA, N.S., BIOLO, S., MEURER, T. and BUENO, N.C. Desmidiaceae do Lago Municipal de Cascavel, 
Paraná, Brasil. Revista Brasileira de Biociências, 2008, 6(1), 19-21.

BURACK, C., CARVALHO, J.K. and MORESCO, C. Inventário de Zygnemaphyceae perifíticas do lago do Parque Municipal Joaquim Teodoro de Oliveira no município de Campo Mourão- Paraná. Revista Iniciare, 2016, 1(1), 33-39.

CASAGRANDE, R. Poluição da bacia hidrográfica do rio Cascavel [Dissertação de Mestrado em Geografia]. Maringá: Universidade Estadual de Maringá, 1996.

CECY, I.I.T., SILVA, S.R.V. and BOCCON, R. Fitoplâncton da Represa do Rio Passaúna, Município de Araucária, Estado do Paraná. I - Divisão Chlorophyta - Família Desmidiaceae. Estudos de Biologia, 1997, 41, 5-32.

ČERNÁ, K. and NEUSTUPA, J. The pH-related morphological variations of two acidophilic species of Desmidiales (Viridiplantae) isolated from a lowland peat bog, Czech Republic. Aquatic Ecology, 2010, 44(2), 409-419. http://dx.doi.org/10.1007/s10452009-9296-х.

CETTO, J.M., LEANDRINI, J.A., FELISBERTO, S.A. and RODRIGUES, L. Comunidade de algas perifiticas no reservatório de Irai, Estado do Paraná, Brasil. Acta Scientiarum. Biological Sciences, 2004, 26(1), 1-7.

COESEL, P.F.M. Structural characteristic and adaptations of desmids communities. Journal of Ecology, 1982, 70(1), 163-177. http://dx.doi.org/10.2307/2259871.

COESEL, P.F.M. Biogeography of desmids. Hydrobiologia, 1996, 336(1-3), 41-53. http://dx.doi.org/10.1007/ BF00010818.

COESEL, P.F.M. A method for quantifying conservation value in lentic freshwater habitats using desmids as indicator organisms. Biodiversity and Conservation, 2001, 10(2), 177-187. http://dx.doi. org/10.1023/A:1008985018197.

COESEL, P.F.M. and KRIENITZ, L. Diversity and geographic distribution of desmids and other coccoid green algae. Biodiversity and Conservation, 2008, 17(2), 381-392. http://dx.doi.org/10.1007/s10531007-9256-5.

DAJOZ, R. Principios de ecologia. Porto Alegre: Artmed, 2005.

FELISBERTO, S.A. and RODRIGUES, L. Influência do gradiente loingitudinal (rio barragem) na similaridade das comunidades de desmídias perifíticas. Revista Brasileira de Botanica. Brazilian Journal of Botany, 2005a, 28(2), 241-254. http://dx.doi.org/10.1590/ S0100-84042005000200005.

FELISBERTO, S.A. and RODRIGUES, L. Comunidades de algas perifíticas nos reservatórios em cascata do rio Paranapanema, Brasil. Acta Scientiarum. Biological Sciences, 2005b, 27(3), 215-223.

FELISBERTO, S.A. and RODRIGUES, L. Cosmarium (Desmidiaceae, Zygnemaphyceae) da ficoflórula perifítica do reservatório de Rosana, bacia do rio Paranapanema, Paraná/São Paulo, Brasil. Hoehnea, 2010a, 37(2), 267-292. http://dx.doi.org/10.1590/ S2236-89062010000200004.

FELISBERTO, S.A. and RODRIGUES, L. Periphytic algal community in artificial and natural substratum in a tributary of the Rosana reservoir (Corvo Stream, Paraná State, Brazil). Acta Scientiarum. Biological Sciences, 2010b, 32(4), 373-385. http://dx.doi. org/10.4025/actascibiolsci.v32i4.4627.

FELISBERTO, S.A. and RODRIGUES, L. Desmidiaceae, Gonatozygaceae e Mesotaeniaceae na comunidade perifítica do reservatório de Salto do Vau (Bacia do rio Iguaçu, PR). Hoehnea, 2008, 35(2), 235-254. http://dx.doi.org/10.1590/S223689062008000200006 .

FELISBERTO, S.A. and RODRIGUES, L. Desmídias epifíticas do reservatório de Rosana, bacia do rio Paranapanema, Paraná/São Paulo, Brasil: Euastrum e Micrasterias (Desmidiaceae). Revista Brasileira de Biociências, 2011, 9(2), 206-213.

FELISBERTO, S.A. and RODRIGUES, L. Dinâmica sucessional de comunidade de algas perifíticas em um ecossistema lótico subtropical. Rodriguésia, 2012, 63(2), 463-473. http://dx.doi.org/10.1590/S217578602012000200018.

FELISBERTO, S.A. and RODRIGUES, L. Gênero Closterium (Closteriaceae) na comunidade perifítica do Reservatório de Salto do Vau, Sul do Brasil. Iheringia. Série Botânica, 2007, 62(1-2), 45-54.

FELISBERTO, S.A. and RODRIGUES, L. Gêneros Staurastrum e Staurodesmus na comunidade perifítica do reservatório de Rosana, Paraná/São Paulo, Brasil. Revista Brasileira de Biociências, 2013, 11, 64-75.

FELISBERTO, S.A., RODRIGUES, L. and SANTOS, H.S. Taxonomical and ecological characteristics of the desmids placoderms in reservoir: analyzing the spatial and temporal distribution. Acta Limnologica Brasiliensia, 2014, 26(4), 392-403. http://dx.doi. org/10.1590/S2179-975X2014000400007.

FERREIRA, F.A., MORMUL, R.P., BIOLO, S. and RODRIGUES, L. Podostemum rutifolium subsp. rutifolium como estruturador da comunidade de algas perifíticas em um rio neotropical. Rodriguésia, 2011., 62(4), 813-825. http://dx.doi.org/10.1590/ S2175-78602011000400009.

FRANSCESCHINI, I. M., BURLINGA, A. L., REVIERS, B., PRADO, J. F., RÉZIG, S.H. Algas: uma abordagem filogenética, taxonômica e ecológica. Porto Alegre: Artmed, 2010.

GOLDSBOROUGH, G. and ROBINSON, G.G.C. Pattern in wetlands. In: R.J. STEVENSON, M.L. BOTHWELL, and R.L. LOWE, eds. Algal ecology: freshwater benthic ecosystems. San Diego: Academic Press, 1996. http://dx.doi.org/10.1016/B978012668450-6/50033-3. 
GONTCHAROV, A.A. and MELKONIAN, M. Molecular phylogeny of Staurastrum Mayen ex Ralfs and related genera (Zygnematophyceae, Streptophyta) based on coding and noncoding rDNA sequence comparisons. Journal of Phycology, 2005, 41(4), 887-889. http://dx.doi.org/10.1111/j.00223646.2005.04165.x.

GRAHAM, L.G. and WILCOX, L.W. Algae. United State of America: Prentice-Hall, 2000.

LOZOVEI, A.L. and HOHMANN, E. Principais gêneros de algas em biótopos de larvas de mosquito de Curitiba, Estado do Paraná, Brasil. III. Levantamento e Constatação da Ecologia. Acta Biológica Paranaense, 1977, 6, 123-152. http://dx.doi.org/10.5380/abpr. v6i0.893.

LOZOVEI, A.L. and LUZ, E. Diptera Culicidae em Curitiba e arredores, 2: alimentação. Arquivos de Biologia e Tecnologia, 1976, 19, 43-83.

MEESTER, L.D. and DECLERCK, S. The study of biodiversity in freshwater habitats: societal relevance and suggestions for priorities in science policy. Hydrobiologia, 2005, 542(1), 1-9. http://dx.doi. org/10.1007/s10750-005-0887-9.

MENEZES, V.C., BUENO, N.C. and BORTOLINI, J.C. Composição florística de Desmidiales (exceto Cosmarium) em um lago subtropical brasileiro. Revista Brasileira de Biociências, 2011 a, 9(4), 465-476.

MENEZES, V.C., BUENO, N.C., BORTOLINI, J.C., BIOLO, S. and SIQUEIRA, N.S. O gênero Cosmarium Corda ex Ralfs (Desmidiaceae) no Reservatório de Itaipu, PR, Brasil. Hoehnea, 2011b, 38(3), 483-493. http://dx.doi.org/10.1590/S223689062011000300006 .

MENEZES, V.C., BUENO, N.C., SOBJAK, T.M., BORTOLINI, J.C. and TEMPONI, L.G. Zygnemaphyceae associada à Utricularia foliosa L. no Parque Nacional do Iguaçu, Paraná, Brasil. Iheringia. Série Botânica, 2013, 68, 5-26.

MORESCO, C., BIOLO, S. and BUENO, N.C. O gênero Micrasterias Agardh ex Ralfs (Desmidiaceae, Zygnemaphyceae) em um lago artificial urbano, Paraná, Brasil. Hoehnea, 2009, 36(2), 349-358. http:// dx.doi.org/10.1590/S2236-89062009000200012.

MOSCHINI-CARLOS, V. Importância, estrutura e dinâmica da comunidade perifítica nos ecossistemas aquáticos continentais. In: M.L.M. Pompêo, ed. Perspectivas da limnologia no Brasil. São Luís: Gráfica e Editora União, 1999. p. 1-11.
PICELLI-VICENTIM, M.M. Desmidias (Zygnemaphyceae) planctônicas do Parque Regional do Iguaçu, Curitiba, estado do Paraná, Brasil: Contribuição ao levantamento [Dissertação de Mestrado em Botânica]. Curitiba: Universidade Federal do Paraná, 1984.

PICELLI-VICENTIM, M.M., TREUERSCH, M. and DOMINGUES, L.L. Fitoplâncton da Represa do Passaúna, Estado do Paraná, Brasil. Hoehnea, 2001, 28(1), 53-76.

PRESCOTT, G.W., BICUDO, C.E.M. and VINYARD, H.T. A synopsis of North American Desmids: part II. Desmidiaceae: Placodermae. Section 4. Lincoln: University of Nebraska Press, 1981.

RUGGIERO, M.A., GORDON, D.P., ORRELL, T.M., BAILLY, N., BOURGOIN, T., BRUSCA, R.C., CAVALIER-SMITH, T., GUIRY, M.D. and KIRK, P.M. A Higher Level Classification of All Living Organisms. PLoS One, 2015, 10(4), e0119248. http://dx.doi.org/10.1371/journal.pone.0119248. PMid:25923521.

SILVA, S.R.V.F. and CECY, I.I.T. Desmídias (Zygnemaphyceae) da área de abrangência da Usina Hidrelétrica de Salto Caxias, Paraná, Brasil, I: Gênero Cosmarium. Iheringia. Série Botânica, 2004, 59(1), 13-26.

STAMENKOVIČ, M. and HANELT, D. Geographic distribution and ecophysiological adaptations of desmids (Zygnematophyceae, Streptophyta) in relation to PAR, UV radiation and temperature: a review. Hydrobiologia, 2017, 787(1), 1-26. http:// dx.doi.org/10.1007/s10750-016-2958-5.

VERCELLINO, I.S. and BICUDO, D.C. Sucessão da comunidade de algas perifíticas em reservatório oligotrófico tropical (São Paulo, Brasil): comparação entre período seco e chuvoso. Revista Brasileira de Botanica. Brazilian Journal of Botany, 2006, 29(3), 363-377. http://dx.doi.org/10.1590/S010084042006000300004

WETZEL, R.G. Limnología. Barcelona: Ediciones Omega S.A., 1981. 679 p.

WETZEL, R.G. Recommendations for future research on periphyton. In: R.G. WETZEL, ed. Periphyton of freshwater ecosystems. Amsterdam: Dr. W. Junk Publishers, 1983. http://dx.doi.org/10.1007/97894-009-7293-3_45.

Received: 21 April 2017 Accepted: 19 March 2018 